Grand Valley State University

ScholarWorks@GVSU

\title{
Links Among Attachment Dimensions, Affect, the Self, and Perceived Support for Broadly Generalized Attachment Styles and Specific Bonds
}

\author{
Robin A. Barry \\ University of lowa \\ Brian Lakey \\ Grand Valley State University, lakeyb@gvsu.edu \\ Edward Orehek \\ University of Maryland
}

Follow this and additional works at: https://scholarworks.gvsu.edu/psy_articles

Part of the Psychology Commons

\section{ScholarWorks Citation}

Barry, Robin A.; Lakey, Brian; and Orehek, Edward, "Links Among Attachment Dimensions, Affect, the Self, and Perceived Support for Broadly Generalized Attachment Styles and Specific Bonds" (2007). Peer Reviewed Articles. 31.

https://scholarworks.gvsu.edu/psy_articles/31

This Article is brought to you for free and open access by the Psychology Department at ScholarWorks@GVSU. It has been accepted for inclusion in Peer Reviewed Articles by an authorized administrator of ScholarWorks@GVSU.

For more information, please contact scholarworks@gvsu.edu. 


\title{
Links Among Attachment Dimensions, Affect, the Self, and Perceived Support for Broadly Generalized Attachment Styles and Specific Bonds
}

\author{
Robin A. Barry \\ University of Iowa \\ Brian Lakey \\ Grand Valley State University \\ Edward Orehek \\ University of Maryland
}

\begin{abstract}
Measures of adult attachment reflect both respondents' broadly generalized styles as well as bonds with specific attachment figures. Using Cronbach, Gleser, Nanda, and Rajaratnam's (1972) Multivariate Generalizability analyses, the authors estimated the extent to which correlations among attachment, affect, the self, and perceived social support occurred for both styles and bonds. In two studies, participants rated attachment, affect, the self, and perceived support when thinking about their mothers, fathers, and romantic partners. In both studies, attachment dimensions reflected specific bonds much more so than generalized styles. When correlations reflected specific bonds, both anxious and avoidant dimensions were strongly linked to high negative affect, low positive affect, and low perceived support. In contrast, evidence for links between attachment and affect was inconclusive when correlations reflected generalized styles. Links between attachment and the self depended on the type of selfconstruct and whether styles or bonds were analyzed.
\end{abstract}

Keywords: attachment; multivariate generalizability; affect; perceived social support; self

$\mathrm{A}$ ttachment theory (Ainsworth, Blehar, Waters, \& Wall, 1978; Bowlby, 1969) has become a topic of great interest to social and personality psychologists who study adult personal relationships (Rholes \& Simpson, 2004a). One reason for this interest is that people with secure attachments report better functioning in a number of important life domains compared to people with insecure attachments (Cassidy \& Shaver, 1999; Rholes \& Simpson, 2004a). Although adult attachment often is conceptualized as a relatively stable, broadly generalized characteristic (i.e., attachment styles; Rholes \& Simpson, 2004b), it is increasingly also viewed as a characteristic of bonds with specific other people (i.e., attachment bonds, Rholes \& Simpson, 2004b). Recent research has shown that self-report measures of adult attachment reflect both broadly generalized styles and specific bonds (Buist, Dekovic, Meeus, \& van Aken, 2004; Cook, 2000). In this article, we used Multivariate Generalizability analyses (Cronbach et al., 1972) to estimate the extent to which attachment dimensions, affect, the self, and perceived support were related when correlations reflected (a) broadly generalized styles and (b) specific bonds.

Authors' Note: The authors thank Brooke Feeney for helpful comments on an earlier draft of this article. Correspondence regarding this article should be sent to Robin Barry, University of Iowa, E11 Seashore Hall, Iowa City, IA 52242; e-mail: robin-barry@uiowa.edu.

PSPB, Vol. 33 No. 3, March 2007 340-353

DOI: $10.1177 / 0146167206296102$

(C) 2007 by the Society for Personality and Social Psychology, Inc. 
Attachment theory has become well known to social and personality psychologists, and so we provide only a brief overview. More extensive treatments of attachment theory can be found in recent edited volumes such as Rholes and Simpson (2004a) and Cassidy and Shaver (1999). In brief, attachment theory states that people are biologically prepared to develop close attachments throughout the lifespan with a few other people, including romantic partners. Securely attached people trust that their attachment figures will be available and helpful and are comfortable with intimacy as well as independence. In contrast, insecurely attached people show more attachment anxiety and/or avoidance than the securely attached. Attachment avoidance refers to discomfort with intimacy. Attachment anxiety refers to a strong desire for intimacy coupled with insecurity and fear of rejection. People's cognitive representations of their histories of close relationships (i.e., working models of self and others) are hypothesized to exert long-lasting and broadly generalized influences on other relationships (Collins, Guichard, Ford, \& Feeney, 2004; Mikulincer \& Shaver, 2004) by launching a variety of cognitive, affective, and behavioral processes that serve to create some continuity in attachments across different people.

According to most theorists, attachment quality is inextricably linked to affect and is a major influence on the development and maintenance of the self (Mikulincer \& Shaver, 2004; Pietromonaco \& Feldman Barrett, 2000). Consistent with these predictions, people with secure attachments (i.e., low attachment anxiety and avoidance) have more favorable affect (Kobak, 1999; Mikulincer, 1995), less depression (Simpson \& Rholes, 2004), less anxiety (Strodl \& Noller, 2003), higher selfesteem (Griffin \& Bartholomew, 1994), healthier selfconcepts (Mikulincer, 1995), and higher perceived social support (Collins \& Feeney, 2000) than do people with insecure attachments.

In examining links among attachment, affect, and the self, most research has conceptualized attachment as a generalized style. Yet, it is also widely recognized that people can have different attachment experiences in different relationships (Baldwin, Keelan, Fehr, Enns, \& Koh-Rangarajoo, 1996; Collins et al., 2004; Fraley \& Brumbaugh; 2004; Fraley \& Shaver, 2000; Pietromonaco $\&$ Feldman Barrett, 2000).

Recent research using the Social Relations Model (SRM; Kenny, 1994) provides quantitative estimates of the extent to which self-reported attachment reflects generalized styles as well as specific bonds. The SRM is a special case of Cronbach et al.'s (1972) Generalizability (G) Theory (Kenny, Mohr, \& Levesque, 2001) and both partition variance into components that reflect different types of influences. When at least some perceivers rate the same targets, variance in ratings can be decomposed into three components: Perceiver, Target, and Relationship effects. As applied to attachment dimensions, Perceiver effects reflect the extent to which perceivers rate their attachment experiences similarly across all targets (on average) and, as such, represent broadly generalized characteristics of perceivers. For example, Perceiver A may report more secure attachment than Perceiver B across a range of important relationships. Target effects reflect the extent to which targets differ in their ability to elicit favorable attachment across all perceivers (on average). For example, Target A may elicit more secure attachments across all perceivers (on average) than does Target B. Relationship effects (i.e., the Perceiver $\times$ Target interaction) reflect systematic disagreement among perceivers in rating their attachment experiences with the same targets. For example, Perceiver A may experience secure attachment with Target A, but not Target B, whereas Perceiver B may experience secure attachment with Target B, but not Target A.

The components identified by G/SRM approaches correspond closely to the concepts of generalized styles and specific bonds in attachment theory. The correspondence is not exact because, unlike G/SRM approaches, attachment theory does not define its key concepts quantitatively. The Perceiver effect appears to correspond directly to the concept of generalized styles because both refer to participants' tendencies to have the same attachment experiences across a number of different people. Attachment bonds appear to reflect the combination of both Target and Relationship effects; that is, apart from the person's broadly generalized style, when a person experiences secure attachment with an attachment figure, this reflects both the figure's ability to elicit secure attachment from everyone (on average) as well as the unique relationship between the person and the attachment figure. For the current article, we will use the concept of specific bonds to refer to the combined Target and Relationship effects for two reasons. First, as just described, the concept of specific bonds appears to correspond most directly to the combination of Target and Relationship effects. Second, obtaining separate estimates of Target and Relationship effects requires that at least some participants rate the same targets. Although such an approach has its merits, it also precludes investigators from studying romantic partners as targets because participants typically do not have the same romantic partners. We included romantic partners as targets in the present studies because of the importance that adult romantic partners have in attachment theory (Rholes \& Simpson, 2004b). This inclusion required a design in which targets were nested within participants, which necessarily combined Target and Relationship effects (a "one perceiver, many targets" design as described by Kenny and Winquist, 2001). 
Two SRM investigations have provided quantitative estimates of the relative strength of attachment bonds and styles. Cook (2000) asked four-person families (mother, father, older adolescent, and younger adolescent) to rate each other on attachment dimensions. For attachment anxiety, $42 \%$ of the variance reflected generalized styles and $51 \%$ reflected specific bonds. For attachment avoidance, $33 \%$ reflected generalized styles and $67 \%$ reflected specific bonds. Buist et al. (2004) used essentially the same design and estimated that generalized styles accounted for $46 \%$ of the variance in overall attachment quality, whereas specific bonds accounted for $40 \%{ }^{1}$

The fact that self-report measures of attachment reflect both styles and bonds complicates the interpretation of studies linking attachment dimensions to affect and the self. When participants rate attachment style in general, or rate only one specific relationship, their scores reflect a blend of participants' generalized attachment styles as well as specific bonds. Similarly, when participants rate their general levels of positive and negative affect or self-esteem, their scores reflect stable individual differences as well as the influences of specific bonds (Lakey \& Scoboria, 2005; Neely et al., 2006). Yet, unless a given study is designed to separate variance into styles and bonds components (i.e., participants rate attachment and related constructs experienced with more than one target), it is not possible to know the extent to which a correlation between insecure attachment and negative affect, for example, reflects generalized styles or specific bonds. As defined by G/SRM approaches, the components that correspond to generalized styles are statistically distinct from the components that correspond to specific bonds, and therefore, each component can have different relations to other constructs (Lakey, Lutz, \& Scoboria, 2004; Lakey \& Scoboria, 2005; Neely et al., 2006). For example, the generalized styles component of attachment may have a stronger link to favorable affect than the specific bonds component, or vice versa. Such distinct patterns of correlations have been observed in studies of social support and social conflict (Lakey et al., 2004; Lakey \& Scoboria, 2005; Neely et al., 2006).

It is important to estimate the extent to which links among attachment, affect, and the self reflect generalized styles and specific bonds for both theoretical and practical reasons. Theoretically, when a person experiences insecure attachment, unfavorable affect, and negative views of the self with a given romantic partner, to what extent does this mean that the person will experience insecure attachment and its correlates with other partners? Alternatively, to what extent are attachment and its correlates only characteristic of the specific bonds between the person and her or his partner (Pietromonaco \& Feldman Barrett, 2000)? Although attachment theory acknowledges the influence of both generalized styles and bonds, most attachment research seems to emphasize the role of generalized styles. However, to our knowledge, the precise contributions of generalized styles to the link between attachment and its correlates have not yet been documented. Practically speaking, if problems in attachment result from generalized styles primarily, then interventions should focus on changing aspects of the person with the attachment style, as is commonly attempted in individual psychotherapy. However, if problems in attachment reflect specific bonds primarily, interventions might target specific bonds, as is commonly attempted in couples' therapy.

Lakey and Scoboria (2005) provided an example of how Multivariate G analyses (Brennan, 2001a; Cronbach et al., 1972; Strube, 2000) can be used to estimate correlations among constructs for generalized styles and specific bonds separately. Whereas $G$ analyses partition variance into components reflecting different kinds of effects, Multivariate $G$ analyses estimate correlations among constructs for each component (see Strube, 2000, for an accessible introduction to Multivariate $G$ analyses). In Lakey and Scoboria's studies, participants listed their most important relationship partners and then rated the supportiveness of and conflict with each partner, as well as participants' affect and self-esteem when with each partner. Perceived support showed the same pattern of correlations with self-esteem and favorable affect for both generalized styles and specific bonds. In contrast, conflict's relation to self-esteem and favorable affect varied for generalized styles and specific bonds. For example, for generalized styles, conflict was related to negative affect but not to low positive affect; that is, participants' characteristic tendency to perceive conflict with other people was related to their characteristic tendency to experience negative affect but not their characteristic tendency to experience positive affect. Yet, when conflict and affect reflected specific bonds, conflict was associated with both high negative and low positive affect; that is, relationship partners that elicited conflict also elicited high negative and low positive affect. Lakey et al. (2004) and Neely et al. (2006) provide additional examples of how correlations among constructs differed, depending on whether the constructs reflected generalized styles or specific bonds.

In addition to examining the correlations among attachment, affect, and the self for both generalized styles and specific bonds, the present study also reexamines the link between perceived support and secure attachment. Previous studies have already documented a link between secure attachment and perceived support (Davis, Morris, \& Kraus, 1998), and Collins and Feeney $(2000,2004)$ have found a number of links between attachment and support seeking as well as between attachment and interpretations of specific supportive actions. However, the 
magnitude of these correlations has been only moderate, indicating that perceived support and secure attachment are mostly distinct constructs. However, there are theoretical and methodological reasons to suspect that perceived support and secure attachment may be more highly related than previous estimates have indicated. Theoretically, definitions of secure attachment include perceived support as a key component (Collins \& Feeney, 2000, 2004). Methodologically, Lakey et al. (2004) found that very strong correlations between constructs were sometimes obscured when research designs did not distinguish between generalized styles and specific bonds. The present research reexamined the links between perceived support and attachment dimensions when the links were estimated separately for both generalized styles and specific bonds. Given that attachment avoidance and perceived support are often viewed as reflecting working models of others, whereas attachment anxiety is often viewed as reflecting working models of the self (Collins et al., 2004), we expected that perceived support would be more strongly negatively correlated with avoidant attachment than with anxious attachment. However, we made no prediction regarding how perceived support and attachment dimensions might correlate differently for generalized styles and specific bonds.

In summary, the present research builds on recent findings that self-report measures of attachment are composed of both generalized styles and specific bonds. We used Multivariate $G$ analyses (Cronbach et al., 1972) to estimate the extent to which the generalized styles and specific bonds components of anxious and avoidant attachment were related to their corresponding components of positive and negative affect, self-concept, and perceived support. These results were expected to provide preliminary estimates of the extent to which the well-documented links among attachment quality, affect, the self, and perceived support reflect generalized styles as well as specific bonds.

\section{STUDY 1}

\section{Method}

\section{Participants}

Participants were 54 undergraduates enrolled in psychology courses at Wayne State University in Detroit, Michigan, a large, urban, state university. Although 54 participants is a small sample for conventional research designs, $G$ designs use repeated measures, which allow for greater statistical power. Participants ranged from 18 to 47 years of age $(M=21)$, of which 43 were women and 11 were men. Thirty-nine percent were of European ancestry, 37\% were of African ancestry, 11\% were of Middle Eastern ancestry, with the remainder reflecting a wide range of other ethnic backgrounds. The ethnic mix of the participants reflected the university's urban character.

All participants reported that they were in ongoing romantic relationships of at least 6 months' duration and had living mothers and fathers (or stepparents). Eighty percent of participants were dating but not living with their romantic partners, $6 \%$ were cohabitating with romantic partners, $7 \%$ were engaged, and $7 \%$ were married to their romantic partners. The duration of participants' romantic relationships ranged from 6 months to 22 years ( $M d n=1.9$ years).

Participants typically rated their biological mothers $(96 \%)$ and fathers $(91 \%)$, with the remainder rating stepparents. When there were questions about whether participants should rate biological or stepparents, participants were instructed to rate the parent with whom they spent the most time. Participants often lived with both parents $(48 \%)$, although some participants lived with their mothers $(13 \%)$ or fathers $(2 \%)$ only, with the remainder reporting a range of living situations (e.g., sharing an apartment with a roommate).

\section{Procedure}

Participants were provided with a questionnaire packet containing instructions and measures. Measures were distributed in class and participants were requested to complete the measures outside of class and return them at subsequent class sessions. After completing the consent form, each participant rated three attachment figures: romantic partner, mother, and father. We asked participants to rate these figures because we expected that parents and romantic partners would be important relationships for young adults. For each attachment figure, participants rated attachment dimensions, the perceived supportiveness of the figure, and participant self-esteem and positive and negative affect when with the figure. Participants completed these measures once for each attachment figure, for all attachment figures. The order in which participants rated attachment figures was randomized. Participants were randomly assigned to complete the measures in 1 of 24 orders. We did not administer measures that asked about participants' typical experiences of attachment or support because such measures cannot be partitioned into sources that reflect generalized styles and specific bonds.

\section{Measures}

Attachment. Participants rated relationship-specific attachment dimensions using a modified version of the Experiences in Close Relationships-Revised (EC-R) measure (Fraley, Waller, \& Brennan, 2000). The scale 
contains 36 items, 18 measuring attachment anxiety and 18 measuring avoidance. Self-report measures of attachment, including the ECR-R, usually instruct respondents to think about significant relationships in general and items refer to the relationship "partner" or "partners." However, for the purpose of this study, the items were changed slightly to refer to the specific attachment figure being rated. For example, "I'm afraid that I will lose my partner's love" was altered to "I'm afraid that I will lose my mother's love" when participants rated their mothers. Cook (2000) and Buist et al. (2004) used similar modifications successfully. In addition, we dropped three anxious attachment items because we questioned their appropriateness for parental relationships in our sample (e.g., "I rarely worry about my partner leaving me"). Four response options ranged from not at all to very much. Internal consistency was .86 for attachment anxiety and .96 for avoidance. $^{2}$

Perceived social support. Participants rated the supportiveness of each attachment figure using the Quality of Relationships Inventory (Pierce, Sarason, \& Sarason, 1991). This scale was designed to assess the supportiveness of specific close relationships. For perceived social support, participants rated seven items, such as "To what extent can you turn to this person for advice about problems?" The scale had four response options, including not at all, a little, quite a bit, and very much. Internal consistency for perceived support was .92 .

Affect. Participants reported levels of positive and negative affect when with each attachment figure using the Positive and Negative Affect Schedule (Watson, Clark, \& Tellegen, 1988). This 20-item scale reflects two, mostly independent, factor analytically derived dimensions of affective experience. Watson et al. (1988) demonstrated the reliability and factorial and convergent validity of the scales. Examples of positive affect items included "proud" and "enthusiastic," and negative affect items included "hostile" and "scared." Participants were asked to rate each item on a scale from 1 through 5, with 1 being very slightly or not at all and 5 being extremely. Internal consistency was .92 for positive affect and .88 for negative affect.

Self-esteem. Participants rated their state self-esteem when with each attachment figure using the State SelfEsteem Scale (Heatherton \& Polivy, 1991). This 20-item measure included three factor analytically derived subscales: appearance, social, and performance self-esteem. Example items were as follows: "I feel confident about my abilities" (performance), "I am dissatisfied with my weight" (appearance, reverse scored), and "I feel that others respect and admire me" (social self-esteem). Four response options ranged from not at all to very much. Internal consistency was .78 for performance selfesteem, .80 for social self-esteem, and .86 for appearance self-esteem.

Statistical analyses. Statistical analyses were based on 162 dyads (each participant rated three attachment figures). First, we conducted univariate $\mathrm{G}$ analysis to estimate the extent to which each construct was composed of generalized styles and specific bonds. Data were analyzed as partially nested, mixed ANOVAs with random factors. Test items (Items) and attachment figures (Attachment Figures) were within-subjects factors, and participants (Perceivers) served as the between-subjects factor. Each participant was a level of the Perceivers factor, and each attachment figure was a level of the Attachment Figures factor. To reduce measurement error, odd and even items for all scales were averaged to form two aggregated items, and each aggregated item was a level of the Items factor. Because each participant rated different attachment figures (i.e., participants did not all have the same mothers, fathers, and romantic partners), attachment figures were nested within perceivers. This is an example of a "one perceiver, many targets design" (1PMT) described by Kenny and Winquist (2001). Therefore, the main effects of Attachment Figures (the Target effect in the SRM) and the Perceiver $\times$ Attachment Figures interaction (the Relationship effect in the SRM) were combined in the Attachment Figures:Perceivers effect.

Variance components and standard errors were computed using restricted maximum likelihood estimation using the variance components procedure in SPSS, Version 11.5.0 (2002). The highest order interaction (Perceivers $\times$ Items $\times$ Attachment Figures:Perceivers) was the error term. A given effect was significant when the lower bound of its $95 \%$ confidence interval was greater than zero. The difference in magnitudes of generalized styles and specific bonds was significant when their $95 \%$ confidence intervals did not overlap. For example, if the $95 \%$ confidence interval for styles was .05 to .35 and the confidence interval for bonds was .43 to .57 , we concluded that the effects for styles and bonds differed significantly. In contrast, if the confidence interval for styles was .15 to .45 and the intervals for bonds were .43 to .57 , we concluded that the effects for styles and bonds did not differ significantly.

Multivariate $G$ analyses were conducted using the computer program $m$ GENOVA (Brennan, 2001b). Following Lakey and Scoboria (2005), significance tests for Multivariate $G$ correlations $(\rho)^{3}$ were based on bootstrapping techniques (Mooney \& Duval, 1993) because there are no traditional parametric significance tests available for these correlations. Bootstrapping estimates 
features of the sampling distribution (e.g., the standard error) by taking multiple, random resamples with replacement from a given study's data. We used the normal approximation method using 50 resamples because $m G E N O V A$ is a stand-alone program that requires manual bootstrapping, and sufficient estimates of standard errors can be obtained with 50 resamples (Mooney \& Duval, 1993). The normal approximation method estimates the standard error of the sampling distribution and then identifies the points on the $\mathrm{z}$ distribution marking conventional probability values. Thus, a Multivariate G correlation was significant when it was 1.96 times larger than its standard error. Correlations between different pairs of constructs differed when their $95 \%$ confidence intervals did not overlap.

Finally, we should note that by definition, it is not possible to estimate correlations between generalized styles and specific bonds components (e.g., between the styles and bonds components of attachment) because G/SRM approaches represent the data for generalized styles and specific bonds incommensurately. The data for generalized styles are represented as columns, whereas the data for specific bonds are represented as Perceiver $\times$ Attachment Figure matrices.

\section{Results}

Univariate $G$ analyses focused on the extent to which attachment anxiety and avoidance were composed of generalized styles and specific bonds. Significant univariate effects were required before proceeding with Multivariate $G$ analyses because correlations among variance components would not be meaningful if there were no significant variance components with which to begin (Kenny, 1994). Table 1 presents the proportion of variance accounted for by generalized styles (i.e., the Perceiver effect) and specific bonds (i.e., the Attachment Figures:Perceivers effect). To simplify the presentation of findings, effects involving items (typically construed as error variance) are not displayed.

The current study's primary focus was on attachment dimensions. As displayed in Table 1, attachment anxiety reflected both generalized styles and specific bonds, and specific bonds accounted for significantly more variance than did generalized styles. For attachment avoidance, there was a significant and large effect for specific bonds, but the effect for generalized styles was not significant. In addition, we estimated the magnitude of generalized styles and specific bonds for perceived support, affect, and self-esteem (see Table 1). The effects of generalized styles and specific bonds were significant for all constructs except that there was no significant effect for generalized styles for perceived support. Positive affect, performance, and social self-esteem were approximately
TABLE 1: Variance Components, Standard Errors, and Proportion of Variance Accounted for by Generalized Styles and Relationship-Specific Bonds in Study 1

\begin{tabular}{|c|c|c|c|}
\hline Source & $\begin{array}{c}\text { Variance } \\
\text { Component }\end{array}$ & $\begin{array}{c}\text { Standard } \\
\text { Error }\end{array}$ & $\begin{array}{l}\text { Proportion } \\
\text { of Variance }\end{array}$ \\
\hline \multicolumn{4}{|l|}{ Attachment anxiety } \\
\hline Generalized style & .035 & .016 & $.17^{*}$ \\
\hline Relationship-specific bond & .105 & .017 & $.51 *$ \\
\hline \multicolumn{4}{|l|}{ Attachment avoidance } \\
\hline Generalized style & .000 & .000 & .00 \\
\hline Relationship-specific bond & .614 & .071 & $.91 *$ \\
\hline \multicolumn{4}{|l|}{ Positive affect } \\
\hline Generalized style & .269 & .096 & $.28 *$ \\
\hline Relationship-specific bond & .524 & .080 & $.55^{*}$ \\
\hline \multicolumn{4}{|l|}{ Negative affect } \\
\hline Generalized style & .104 & .047 & $.20 *$ \\
\hline Relationship-specific bond & .296 & .048 & $.57^{*}$ \\
\hline \multicolumn{4}{|l|}{ Performance self-esteem } \\
\hline Generalized style & .103 & .031 & $.37^{*}$ \\
\hline Relationship-specific bond & .076 & .016 & $.27^{*}$ \\
\hline \multicolumn{4}{|l|}{ Social self-esteem } \\
\hline Broadly generalized style & .137 & .043 & $.35^{*}$ \\
\hline Relationship-specific bond & .111 & .021 & $.28 *$ \\
\hline \multicolumn{4}{|l|}{ Appearance self-esteem } \\
\hline Generalized style & .442 & .102 & $.61 *$ \\
\hline Relationship-specific bond & .090 & .021 & $.12 *$ \\
\hline \multicolumn{4}{|l|}{ Perceived social support } \\
\hline Generalized style & .000 & .000 & .00 \\
\hline Relationship-specific bond & .528 & .064 & $.83 *$ \\
\hline
\end{tabular}

$" p<.05$.

equally composed of generalized styles and specific bonds. In contrast, negative affect and perceived support reflected specific bonds significantly more so than generalized styles. Appearance self-esteem reflected generalized styles significantly more so than specific bonds.

The primary goal of the present study was to use Multivariate $G$ analyses to examine the extent to which attachment dimensions were related to affect and selfesteem for both generalized styles and specific bonds (see Table 2). For specific bonds, both attachment anxiety and attachment avoidance were significantly correlated in the expected way with negative affect, low positive affect, and each of the three dimensions of selfesteem; that is, attachment figures that elicited attachment anxiety and/or attachment avoidance also elicited high negative affect and low positive affect, as well as low performance, social, and appearance self-esteem. The correlations between both attachment dimensions and negative affect were strong, and the negative correlation between attachment avoidance and positive affect was especially strong.

For generalized styles, attachment anxiety was significantly correlated with low performance and social selfesteem but not appearance self-esteem; that is, people who characteristically experienced high levels of attachment anxiety also had characteristically low levels of 
TABLE 2: Multivariate Generalizability Correlations (and Standard Errors) for Generalized Styles and Relationship-Specific Bonds for Study 1

\begin{tabular}{|c|c|c|c|c|c|c|c|c|}
\hline & $A n x A t t$ & $A v d A t t$ & $P A$ & $N A$ & PSE & SSE & $A S E$ & PSS \\
\hline \multicolumn{9}{|l|}{ AnxAtt } \\
\hline Styles & - &.$x x(x x)$ & $.01(.36)$ & $.30(.46)$ & $-.52 *(.23)$ & $-.69 *(.22)$ & $-.44(.27)$ &.$x x(x x)$ \\
\hline Bonds & - & $.49 *(.07)$ & $-.28 *(.07)$ & $.61 *(.07)$ & $-.42 *(.13)$ & $-.44 *(.14)$ & $-.24 *(.07)$ & $-.48 *(.09)$ \\
\hline \multicolumn{9}{|l|}{ AvdAtt } \\
\hline Styles & & - &.$x x(x x)$ &.$x x(x x)$ &.$x x(x x)$ &.$x x(x x)$ &.$x x(x x)$ &.$x x(x x)$ \\
\hline Bonds & & - & $-.80 *(.05)$ & $.62 *(.06)$ & $-.42 *(.08)$ & $-.36^{*}(.08)$ & $-.22 *(.11)$ & $-.87 *(.03)$ \\
\hline \multicolumn{9}{|l|}{ PA } \\
\hline Styles & & & - & $-.09(.38)$ & $.21(.29)$ & $.26(.20)$ & $.12(.20)$ &.$x x(x x)$ \\
\hline Bonds & & & - & $-.53 *(.09)$ & $.38 *(.09)$ & $.24 *(.09)$ & $.18^{\dagger}(.11)$ & $.70 *(.06)$ \\
\hline \multicolumn{9}{|l|}{ NA } \\
\hline Styles & & & & - & $-.34(.28)$ & $-.59 *(.23)$ & $-.40^{\dagger}(.23)$ &.$x x(x x)$ \\
\hline Bonds & & & & - & $-.55 *(.10)$ & $-.48 *(.11)$ & $-.23 *(.11)$ & $-.51 *(.07)$ \\
\hline \multicolumn{9}{|l|}{ PSE } \\
\hline Styles & & & & & - & $.63 *(.18)$ & $.38 *(.16)$ &.$x x(x x)$ \\
\hline Bonds & & & & & - & $.72 *(.09)$ & $.37 *(.10)$ & $.36 *(.08)$ \\
\hline \multicolumn{9}{|l|}{ SSE } \\
\hline Styles & & & & & & - & $.71 *(.12)$ &.$x x(x x)$ \\
\hline Bonds & & & & & & - & $.40 *(.10)$ & $.26 *(.09)$ \\
\hline \multicolumn{9}{|l|}{ ASE } \\
\hline Styles & & & & & & & - &.$x x(x x)$ \\
\hline Bonds & & & & & & & - & $.26 *(.10)$ \\
\hline \multicolumn{9}{|l|}{ PSS } \\
\hline Styles & & & & & & & & - \\
\hline Bonds & & & & & & & & - \\
\hline
\end{tabular}

NOTE: $\mathrm{xx}$ indicates the correlation was not estimated because of nonsignificant, univariate variance. AnxAtt $=$ anxious attachment, AvdAtt $=$ avoidant attachment, $\mathrm{PA}=$ positive affect, $\mathrm{NA}=$ negative affect, $\mathrm{PSE}=$ performance self-esteem, $\mathrm{SSE}=$ social self-esteem, ASE $=$ appearance self-esteem, PSS $=$ perceived social support.

${ }^{\dagger} p<.10 .{ }^{*} p<.05$.

performance and social self-esteem. Surprisingly, attachment anxiety was not significantly related to either low positive affect or high negative affect for generalized styles. There was no significant effect for generalized styles for attachment avoidance, and therefore, it was not meaningful to estimate correlations for that component.

Next, we examined correlations between attachment dimensions and perceived social support. For specific bonds, both attachment anxiety and avoidance were related to low perceived support; that is, attachment figures that elicited high levels of attachment anxiety and/or avoidance also elicited low perceived support. The correlation between attachment avoidance and low perceived support was so strong as to suggest that the two constructs were nearly identical for specific bonds. As described previously, differences between correlations were significant when their $95 \%$ confidence intervals did not overlap. By this criterion, the correlation between the specific bonds components of attachment avoidance and low perceived support was significantly stronger than the correlation between the specific bonds components of attachment anxiety and low perceived support. It was not meaningful to estimate correlations involving either perceived support or attachment avoidance for generalized styles because there was no significant generalized styles variance for these constructs.
In addition to attachment, we also estimated Multivariate $G$ correlations among the other constructs (see Table 2). Positive affect and negative affect were weakly, negatively, and nonsignificantly correlated for generalized styles but were moderately, negatively correlated for specific bonds. Perceptions of social support were strongly positively related to positive affect as well as to performance, social, and appearance self-esteem for specific bonds. Perceived support was strongly negatively related to negative affect for specific bonds. For perceived support, there was no evidence of variation for the generalized styles component and so it was not meaningful to estimate correlations for this component. The three dimensions of self-esteem were moderately to strongly intercorrelated for both generalized styles and specific bonds.

\section{Discussion}

Consistent with previous research (Buist et al., 2004; Cook, 2000), we found that self-report measures of adult attachment anxiety and avoidance reflected both generalized styles and specific bonds. More important, when correlations reflected specific bonds, attachment anxiety and avoidance were related strongly to high negative affect; low positive affect; low performance, social, and 
appearance self-esteem; and low perceived support. Phrased differently, attachment figures that elicited attachment anxiety and/or avoidance also elicited less favorable affect, lower self-esteem, and less perceived support than did figures that elicited low anxiety and/or avoidance. In contrast, links among attachment dimensions and affect were not observed when these correlations reflected generalized styles. For generalized styles, attachment anxiety was not related to unfavorable affect, although attachment anxiety was related to low performance and social self-esteem (but not appearance self-esteem). Phrased differently, individuals who characteristically saw their attachment figures as evoking attachment anxiety characteristically experienced low performance and social self-esteem as well, but not unfavorable affect. There was no significant styles variance for attachment avoidance, and therefore, we could not estimate the correlations involving this component. This study contributes to adult attachment research by providing a first estimate of the extent to which the welldocumented links among attachment dimensions, affect, self-esteem, and perceived social support reflect generalized styles and specific bonds. Although there was strong evidence that links between attachment dimensions and affect reflected specific bonds, there was little evidence for the role of generalized styles.

In interpreting these findings, it is important to consider the comparability of the current study's estimates to those of other investigators. With regard to attachment anxiety and avoidance, we estimated larger effects for specific bonds than for generalized styles, whereas the estimates of Buist et al. (2004) and Cook (2000) suggested more even contributions of bonds and styles. This difference may reflect (in part) that the current study assessed romantic partners as well as mothers and fathers among predominantly young adults, whereas previous studies assessed mothers, fathers, and similarly aged siblings in samples of young adolescents. Romantic relationships may have stronger effects on attachment than do other forms of relationships, and if so, the current sample should have observed stronger effects for specific bonds compared to previous research. In addition to sample differences, Cook and Buist et al. calculated effect sizes differently than most G/SRM studies (Cook, 1994), including the current study. Cook's method analyzes variance in a round robin design separately for each family role (e.g., mother, father), whereas most G/SRM studies pool variance across roles. When variance is pooled across all roles in the Cook (2000, Table 1) and Buist et al. (Table 3) studies, their results are much more similar to the results of the present study. For attachment anxiety, Cook (2000) found that $22 \%$ of the variance reflected generalized styles and $77 \%$ reflected specific bonds. For attachment avoidance, 17\%
TABLE 3: Variance Components, Standard Errors, and Proportion of Variance Accounted for by Generalized Styles and Relationship-Specific Bonds in Study 2

\begin{tabular}{|c|c|c|c|}
\hline Source & $\begin{array}{c}\text { Variance } \\
\text { Component }\end{array}$ & $\begin{array}{c}\text { Standard } \\
\text { Error }\end{array}$ & $\begin{array}{l}\text { Proportion } \\
\text { of Variance }\end{array}$ \\
\hline \multicolumn{4}{|l|}{ Attachment anxiety } \\
\hline Generalized style & .042 & .020 & $.17^{*}$ \\
\hline Relationship-specific bond & .142 & .020 & $.57 *$ \\
\hline \multicolumn{4}{|l|}{ Attachment avoidance } \\
\hline Generalized style & .086 & .048 & $.15^{\dagger}$ \\
\hline Relationship-specific bond & .460 & .060 & $.78 *$ \\
\hline \multicolumn{4}{|l|}{ Positive affect } \\
\hline Generalized style & .167 & .071 & $.19 *$ \\
\hline Relationship-specific bond & .526 & .073 & $.59 *$ \\
\hline \multicolumn{4}{|l|}{ Negative affect } \\
\hline Generalized style & .100 & .032 & $.29 *$ \\
\hline Relationship-specific bond & .192 & .027 & $.55^{*}$ \\
\hline \multicolumn{4}{|l|}{ Actual/ideal discrepancies } \\
\hline Generalized style & 3.889 & .826 & $.62 *$ \\
\hline Relationship-specific bond & 1.977 & .268 & $.31 *$ \\
\hline \multicolumn{4}{|l|}{ Actual/ought discrepancies } \\
\hline Generalized style & 3.42 & .748 & $.58 *$ \\
\hline Relationship-specific bond & 2.04 & .280 & $.34 *$ \\
\hline \multicolumn{4}{|l|}{ Perceived social support } \\
\hline Generalized style & .091 & .051 & $.14^{\dagger}$ \\
\hline Relationship-specific bond & .463 & .062 & $.72 *$ \\
\hline
\end{tabular}

${ }^{\dagger} p<.10 .{ }^{*} p<.05$.

reflected generalized styles and $83 \%$ reflected specific bonds. Buist et al. estimated that generalized styles accounted for $30 \%$ of the variance in overall attachment quality, whereas specific bonds accounted for $68 \%$. Thus, the difference in estimates for the relative strength of bonds and styles between Study 1 and previous studies appears to largely reflect the method by which effect sizes are calculated.

Nonetheless, Study 1 appeared to underestimate the generalized styles component for perceived support, compared to Lakey and Scoboria's (2005) estimate. Given the similarity between perceived support and attachment avoidance, the generalized styles components for attachment avoidance may have been underestimated as well. Study 2 will provide additional estimates of the style components for perceived support and attachment avoidance. Except for the differences just described, our other findings were remarkably similar to Lakey and Scoboria's previous estimates. For example, specific bonds that elicited high perceived support also elicited favorable affect and self-esteem. Negative affect and low positive affect were related moderately strongly when they reflected specific bonds but not when they reflected generalized styles. Appearance self-esteem reflected generalized styles more so than specific bonds, whereas performance and social self-esteem were more equally composed of styles and bonds components. 


\section{STUDY 2}

The primary purpose of Study 2 was to replicate the findings involving attachment dimensions and affect from Study 1 as well as to explore attachment dimensions' relationships to self-discrepancy, another aspect of the self (Higgins, 1987). Mikulincer has argued that focusing on self-esteem exclusively in attachment research ignores important complexity in the self-system, which is better captured by studying constructs such as self-discrepancy.

Self-discrepancy theory (Higgins, 1987) proposes that conflicting beliefs about the self lead to emotional distress. Such conflicts can involve three domains of the self (the actual, ideal, and ought selves) as well as whether the self is construed from one's own standpoint or one's perception of a significant other's standpoint. Higgins (1987) hypothesized that discrepancies between specific domains and standpoints were related to specific affective states. For example, discrepancies between the actual self (how one actually is) and ideal self (how one ideally should be) have been related to dejection-related emotions such as disappointment, dissatisfaction, and sadness (Higgins, Bond, Klein, \& Strauman, 1986) as well as clinical depression (Strauman, 1989). Discrepancies between the actual self and how one ought to be (i.e., the ought self) have been related to fear, agitation, and clinical anxiety (Higgins et al., 1986; Strauman, 1989).

Self-discrepancy seems especially relevant to attachment because unlike self-esteem, self-discrepancy explicitly involves links between mental representations of self and others. Mikulincer (1995, Study 5) found that insecurely attached people had significantly more discrepancies (from their own point of view) between actual-ideal and actual-ought selves than did securely attached people. Within the insecurely attached groups, no differences were found between avoidant and anxiousambivalent people. In the present Study 2, we expanded on Mikulincer's Study 5 by examining how self-discrepancies were related to attachment dimensions for both generalized styles and specific bonds. Mikulincer interpreted his findings as reflecting generalized styles. However, Study 1 's observation of strong correlations between attachment dimensions and self-esteem for specific bonds raises the possibility that links between attachment dimensions and self-discrepancies may reflect specific bonds as well as generalized styles.

\section{Method}

\section{Participants}

Participants were 66 undergraduates enrolled in psychology courses at Wayne State University in Detroit,
Michigan, a large, urban university. Participants ranged from 18 to 39 years of age $(M=23)$, of which 58 were women and 8 were men. Forty-two percent were of European ancestry, 26\% were of African ancestry, and $12 \%$ each were of Middle Eastern and Latin American ancestry. The remainder reflected a wide range of ancestries.

As in Study 1, participants were in romantic relationships of at least 6 months duration and had living mothers and fathers (or stepparents). Of participants, 64\% were dating but not living with their romantic partners, $11 \%$ were dating and cohabitating with romantic partners, $9 \%$ were engaged, and $17 \%$ were married. The duration of participants' current romantic relationships ranged from 7 months to 22 years $(M d n=2.6$ years).

The majority of participants $(95 \%)$ rated their biological mothers, $92 \%$ rated their biological fathers, and the remainder rated stepparents. Thirty-two percent lived with both parents, $14 \%$ lived with their mothers only, and 3\% lived with their fathers only. The remaining participants reported a range of living arrangements.

\section{Procedure}

Procedures were the same as in Study 1 except that participants completed measures in hour-long sessions in a psychology laboratory and participants completed a measure of self-discrepancy rather than a measure of self-esteem.

\section{Measures}

The internal consistencies of the measures in Study 2 were .87 for attachment anxiety, .96 for attachment avoidance, .93 for perceived support, .91 for positive affect, and .91 for negative affect.

Self-discrepancy. Participants completed the Selves Questionnaire (Higgins et al., 1986). This questionnaire assesses self-discrepancy from multiple domains (i.e., actual, ideal, and ought) and multiple standpoints (i.e., self and important others). Participants were asked to list up to 10 attributes describing themselves (actual self) and then to rate the extent to which they possessed each attribute. Next, for all attachment figures, participants listed up to 10 attributes that participants believed their attachment figures (a) ideally would like participants to possess and (b) thought participants ought to possess. Participants completed a separate list for each attachment figure. Participants also rated the extent to which attachment figures thought participants ideally would or ought to have these attributes. Definitions of each domain (actual, ideal, and ought) were provided on a separate cover sheet. Extent ratings ranged from 1 to 4 , with 1 representing slightly and 4 representing extremely. 
TABLE 4: Multivariate Generalizability Correlations (and Standard Errors) for Generalized Styles and Relationship-Specific Bonds for Study 2

\begin{tabular}{|c|c|c|c|c|c|c|c|}
\hline & $A n x A t t$ & $A v d A t t$ & $P A$ & $N A$ & $A I$ & $A O$ & PSS \\
\hline \multicolumn{8}{|l|}{ AnxAtt } \\
\hline Style & - & $.70 *(.20)$ & $-.49 *(.21)$ & $.84 *(.12)$ & $.14(.25)$ & $.25(.27)$ & $-.93 *(.09)$ \\
\hline Bond & - & $.53 *(.05)$ & $-.40 *(.08)$ & $.58 *(.07)$ & $.05(.08)$ & $.19^{\dagger}(.10)$ & $-.59 *(.05$ \\
\hline \multicolumn{8}{|l|}{ AvdAtt } \\
\hline Style & & - & $-.21(.35)$ & $.43^{\dagger}(.23)$ & $.50 *(.24)$ & $.49 *(.25)$ & $-.75^{\dagger}(.42)$ \\
\hline Bond & & - & $-.78 *(.03)$ & $.56 *(.06)$ & $-.03(.10)$ & $.10(.10)$ & $-.86 *(.03$ \\
\hline \multicolumn{8}{|l|}{ PA } \\
\hline Style & & & - & $-.16(.25)$ & $-.73 *(.15)$ & $-.53 *(.18)$ & $.41^{\dagger}(.24)$ \\
\hline Bond & & & - & $-.46 *(.06)$ & $.05(.09)$ & $-.16(.09)$ & $.72 *(.05$ \\
\hline \multicolumn{8}{|l|}{ NA } \\
\hline Style & & & & - & $.05(.16)$ & $.11(.17)$ & $-.80 *(.15$ \\
\hline Bond & & & & - & $.10(.08)$ & $.14(.08)$ & $-.56 *(.06$ \\
\hline \multicolumn{8}{|l|}{$\mathrm{AI}$} \\
\hline Style & & & & & - & $.94 *(.03)$ & $-.46 *(.23)$ \\
\hline Bond & & & & & - & $.46 *(.06)$ & $-.03(.10)$ \\
\hline \multicolumn{8}{|l|}{$\mathrm{AO}$} \\
\hline Style & & & & & & - & $-.46 \dagger(.28$ \\
\hline Bond & & & & & & - & $-.13(.11)$ \\
\hline \multicolumn{8}{|l|}{ PSS } \\
\hline Style & & & & & & & - \\
\hline Bond & & & & & & & - \\
\hline
\end{tabular}

NOTE: AnxAtt $=$ anxious attachment, AvdAtt $=$ avoidant attachment, $\mathrm{PA}=$ positive affect, $\mathrm{NA}=$ negative affect, $\mathrm{AI}=\mathrm{actual} / \mathrm{own}-\mathrm{ideal} / \mathrm{other}$ self-discrepancy, $\mathrm{AO}=$ actual/own-ought/other self-discrepancy, PSS = perceived social support.

${ }^{\dagger} p<.10 .{ }^{*} p<.05$.

We calculated self-discrepancies by comparing participants' descriptions of how they believed they actually were (actual/own) with (a) participants' descriptions of how each of their attachment figures wished participants were (e.g., actual/own-ideal/mother discrepancy) as well as (b) participants' descriptions of how each of their attachment figures thought participants ought to be (e.g., actual/own-ought/mother discrepancy). Two raters were trained to calculate discrepancy scores utilizing Higgins et al.'s (1986) procedure and independently rated all participants' self-discrepancy protocols. Positive scores indicated greater discrepancy. Interrater reliability was .96.

\section{Results}

Statistical analyses were based on 198 dyads (each participant rated three attachment figures). As in Study 1, we first conducted $G$ analyses to estimate the extent to which each construct was composed of both generalized styles and specific bonds. As displayed in Table 3, the results of Study 2 were quite similar to the estimates from Study 1 . As in Study 1, both attachment anxiety and avoidance had strong and significant specific bonds effects, and for both constructs, specific bonds had stronger effects than did generalized styles. There was a significant effect for generalized styles for attachment anxiety and a marginally significant $(p<.10)$ effect for generalized styles for attachment avoidance. Regarding self-discrepancies, there were sizeable and significant effects for generalized styles and specific bonds for both actual/own-ought/other and actual/own-ideal/other discrepancies, and the magnitude of the effects for generalized styles and specific bonds did not differ significantly. Consistent with Study 1, there was a significant specific bonds effect for perceived support and specific bonds were significantly stronger than generalized styles, which were only marginally significant. Finally, there also were significant effects for generalized bonds and specific styles for both positive and negative affect. However, in contrast to Study 1 and Lakey and Scoboria (2005), the magnitude of the effects for generalized bonds and specific styles did not differ for negative affect, whereas for positive affect, specific bonds were significantly stronger than generalized styles.

The primary goal of Study 2 was to replicate the Multivariate $\mathrm{G}$ correlations among attachment dimensions, affect, and perceived support for both generalized styles and specific bonds as well as to extend these analyses to measures of self-discrepancy. As in Study 1, both attachment anxiety and attachment avoidance were significantly correlated with both low positive affect and high negative affect when correlations reflected specific bonds (see Table 4); that is, the attachment figures that elicited attachment anxiety and/or avoidance also elicited high negative affect and low positive affect. As in Study 1, the correlation was particularly strong between attachment avoidance and low positive affect. In addition, consistent with Study 1, attachment anxiety was moderately correlated with low 
perceived social support and attachment avoidance was especially strongly correlated with low perceived support for specific bonds. As with Study 1, the strength of the correlation for the specific bonds components of low perceived support and attachment avoidance was significantly greater than the strength of the correlation for the specific bonds components of low perceived support and attachment anxiety. Attachment anxiety and avoidance were moderately related for specific bonds.

Unlike Study 1, participants who characteristically experienced high attachment anxiety also characteristically experienced low positive affect, high negative affect, and low perceived support. In addition, there was a trend $(p<.10)$ for participants who characteristically experienced high attachment avoidance to also characteristically experience high negative affect and low perceived support but not low positive affect. Finally, participants who characteristically experienced attachment anxiety also characteristically experienced avoidance.

Links between self-discrepancy and the other constructs occurred primarily for generalized styles. Participants who characteristically experienced actual-ought and actual-ideal discrepancies also characteristically experienced attachment avoidance, low perceived support, and low positive affect. However, for specific bonds, there was only one marginally significant correlation: Attachment figures that elicited attachment anxiety also elicited actual-ought discrepancies. No type of self-discrepancy was related to negative affect in any analyses. For generalized styles, actual-ought and actual-ideal discrepancies were so highly correlated that they were functionally equivalent. The two forms of discrepancies were less highly correlated for relationship specific bonds.

\section{Discussion}

Study 2 substantially replicated the results of Study 1 for links between attachment dimensions and affect when the links reflected specific bonds. To our knowledge, these are the first studies to provide evidence that the links among attachment dimensions and affect reflect, at least in part, the effects of specific bonds, and the results raise the question of the extent to which previous studies on attachment, affect, the self, and perceived support also reflected specific bonds primarily.

In contrast, when correlations reflected generalized styles, evidence for links between affect and attachment dimensions was less consistent across the two studies. This may have resulted partly from the fact that there were many more observations available for estimating the specific bonds components than for the generalized styles components. Because we used bootstrapped estimates of standard errors, correlations involving the generalized styles components were based on the number of participants (54 and 66 for Studies 1 and 2, respectively), whereas correlations involving the specific bonds components were based on the Participant $\times$ Attachment Figure matrix (162 and 198 observations, respectively). Consistent with this reasoning, the standard errors for correlations involving bond components were consistently larger than the standard errors for the style components (see Tables 2 and 4). Thus, the sample sizes for estimating correlations among the generalized styles components may not have permitted sufficiently reliable estimates. Additional estimates will be needed to obtain a clearer picture of the link between attachment and affect for generalized styles. In this regard, Merlo (2005) conducted a similar study with a much larger sample of high school students, most of whom rated parents and best friends instead of romantic partners. In addition to replicating the results reported here for specific bonds, Merlo also found strong correlations between attachment anxiety (but not avoidance) and subclinical depressive symptoms for generalized styles. Thus, with regard to generalized styles, the results of Study 2 appear to be more generalizable than those of Study 1 .

Whereas the links between different aspects of selfesteem did not differ depending on whether the correlations reflected styles or bonds (Study 1), actual-ideal and actual-ought discrepancies differed substantially in their correlation depending on whether styles or bonds were examined (Study 2). Moreover, ideal and ought discrepancies were not distinguishable $(\rho=.94)$ when they reflected participant's characteristic tendencies to experience self-discrepancies, yet discrepancies diverged substantially $(\rho=.46)$ when they reflected specific bonds. Thus, specific attachment figures elicited substantially different patterns of self-discrepancies compared to other attachment figures and compared to participants' characteristic self-discrepancies. Such a pattern is consistent with a large body of research in social cognition that indicates that specific attachment figures can elicit distinct representations of the self (Andersen, Reznik, \& Manzella, 1996). Although the strong correlations between actualought and actual-ideal discrepancies for the generalized styles components may surprise some readers, similarly strong correlations have been observed (Gonnerman, Parker, Lavine, \& Huff, 2000) when samples were not preselected on the basis of high scores on one dimension and low scores on another, a common practice in selfdiscrepancy research (e.g., Strauman \& Higgins, 1987).

Attachment anxiety and avoidance appeared to be related to different types of self-constructs depending on whether generalized styles or specific bonds were studied. For self-esteem, links between attachment dimensions and the self appeared to reflect both specific bonds and generalized styles. However, links between attachment dimensions and self-discrepancies appeared to 
reflect generalized styles primarily. Mikulincer (1995) interpreted his observation of links between attachment and self-discrepancies as reflecting generalized styles, and the results of Study 2 support this interpretation.

Finally, the results of both studies replicated Lakey and Scoboria's (2005) findings that perceived support was related to high positive affect and low negative affect when correlations reflected specific bonds. In addition, both studies replicated Lakey and Scoboria's finding that whereas positive and negative affects were only weakly correlated for generalized styles $(\rho=-.09$ and -.16), they were moderately strongly correlated for specific bonds $(\rho=-.53$ and -.46). Thus, the structure of affect appears to differ somewhat depending on whether affect reflects trait-like or relationship-specific components.

\section{GENERAL DISCUSSION}

The present studies are consistent with much current thinking in attachment research (Collins et al., 2004; Fraley \& Brumbaugh, 2004; Pietromonaco \& Feldman Barrett, 2000; Rholes \& Simpson, 2004b) in that they isolated the aspect of attachment that reflected generalized styles from the aspect that reflected specific bonds. Consistent with previous research (Buist et al., 2004; Cook, 2000), attachment dimensions were composed of distinct styles and bonds components, and as operationalized by G/SRM approaches, each component was statistically and conceptually distinct. Therefore, it was important to map the nomological networks separately for each component because there can be important differences in the networks for separate components of the same construct (Lakey et al., 2004; Lakey \& Scoboria, 2005; Neely et al., 2006). The current studies found strong evidence that specific bonds play an important role in the links between attachment dimensions and affect, self-esteem, and perceived social support, whereas the role for generalized styles was less consistent.

Some readers may be surprised that the attachment measures reflected specific bonds more so than generalized styles and that affect and attachment dimensions were more strongly related when these constructs reflected specific bonds than generalized styles. If replicated in other samples, this may mean that self-report measures of attachment dimensions reflect the qualities of specific relationships more so than trait-like individual differences and, as such, may have more in common with constructs such as perceived social support than with personality. However, we do not encourage readers to switch their interpretation of attachment measures from reflecting individual differences to reflecting personal relationships. Rather, attachment measures, similar to measures of social support, affect, and the self, are composed of a blend of both trait-like and relationshipspecific components. Thus, we urge readers to consider using approaches that can cleanly distinguish between trait-like and relationship-specific components and can estimate correlations with other constructs separately for each component. Such approaches should provide more precise descriptions of the extent to which correlations between attachment dimensions and other constructs reflect both attachment styles and bonds.

Social cognitive accounts of attachment processes (Baldwin et al., 1996; Collins et al., 2004; Mikulincer \& Shaver, 2004) can easily explain correlations among constructs for both generalized styles and specific bonds by drawing on the concept of construct accessibility (Higgins, 1996). Construct accessibility refers to the probability that a given construct will be used to interpret a stimulus given that the construct is applicable and available. Constructs can be made more accessible because something about the situation encourages its use (e.g., primes in experimental studies), and constructs can be chronically accessible in the sense that people differ in their characteristic use of certain constructs apart from any particular situational inducement. Specific bonds might reflect situationally induced construct accessibility, in which the situation is the specific attachment figure held in mind when participants make their ratings. Generalized styles might reflect chronically accessible constructs in that the styles represent typical thoughts about attachment, averaged across situational inductions (i.e., attachment figures).

The current studies also provide additional insight into the extent to which attachment dimensions and social support are related. Previous studies have already documented an empirical link between attachment and support and most definitions of secure attachment include the perceived supportiveness of attachment figures (Collins \& Feeney, 2000, 2004; Davis et al., 1998). However, the present studies suggest that attachment avoidance and low perceived social support may be the same construct when both reflect specific bonds. In both studies, the two constructs were very highly correlated ( $\rho$ s $=-.87$ and -.86 ) and demonstrated essentially the same patterns of correlations with other constructs. Attachment anxiety was substantially but significantly less highly correlated with low perceived support ( $\rho s=-.48$ and -.59) for specific bonds. Thus, at least with regard to specific bonds, perceived support and low avoidant attachment might reflect the same construct. If confirmed by subsequent research, such unity could provide a strong basis for integrating the attachment and social support literatures.

Finally, we should note some of the limitations of this research. First, as discussed previously, the sample sizes may not have been sufficient to provide good estimates for correlations involving generalized styles. Larger samples 
will be needed to improve on these estimates. Second, there is currently substantial discussion about what constitutes an attachment relationship (Fraley \& Shaver, 2000), and some of the specific relationships studied may not have involved true attachment figures. If so, the relationships in the current study should have been less powerful and this should have underestimated effects due to specific bonds and overestimated effects due to generalized styles. Third, studying each participant's own mother, father, and romantic partner required a design in which attachment figures were nested within participants. This resulted in the confounding of two potentially important sources of variance: partner (i.e., attachment figures) and relationship effects. As revealed by Buist et al. (2004) and Cook (2000), self-report attachment measures are influenced by both partners and relationships, and future research should attempt to estimate the extent to which attachment dimensions, affect, and the self are related for both of these components. Fourth, the current study only investigated the perspectives of participants and it may be useful to include the perspectives of independent observers as well, as in Collins and Feeney (2000, 2004). Finally, the current sample was composed of college students and it will be necessary to determine the extent to which the results generalize to other groups. It would be especially interesting to study clinical samples, especially personalitydisordered patients, who might show stronger effects for broadly generalized styles.

In summary, the current studies used Multivariate G analyses to estimate the correlations among attachment dimensions, affect, the self, and perceived support for generalized styles as well as specific bonds. Attachment anxiety and avoidance were more strongly influenced by specific bonds than generalized styles, and the correlations between attachment dimensions and affect were strong and consistent when correlations reflected specific bonds. In addition, perceived support and attachment avoidance appeared to reflect the same construct when correlations reflected specific bonds. In contrast, correlations among these constructs were inconsistent across studies when they reflected generalized styles. Links between attachment and the self depended on the type of self-construct as well as whether correlations reflected generalized styles or specific bonds. In sum, these studies demonstrated how Multivariate $G$ analyses can isolate attachment styles from bonds and can examine each component's links to other constructs within a unified analytic framework.

\section{NOTES}

1. To arrive at these estimates, we combined the target and relationship effects as reported in the original articles. In both studies, the relationship component of attachment was approximately twice as strong as the partner component.
2. In most psychological research, internal consistency is estimated only for differences among persons because effects due to social context (Attachment Figures:Perceivers in the current study) are not estimated. However, because the present research estimated effects for both Perceivers and Attachment Figures:Perceivers, we calculated internal consistency as $\alpha=\left(\sigma_{p}^{2}+\sigma_{A F: P}^{2}\right) /\left(\left(\sigma_{p}^{2}+\sigma_{A F: P}^{2}\right)+\left(\sigma_{P x I}^{2} / n_{i}\right)+\left(\sigma_{A F F P x I}^{2} / n_{i}\right)\right)$, where $P$ indicates perceivers, $A F$ indicates attachment figures, and $I$ indicates items.

3. $\rho$ is used to represent Multivariate G correlations because these correlations are estimates of population values (Brennan, 2001a).

\section{REFERENCES}

Ainsworth, M. D. S., Blehar, M. C., Waters, E., \& Wall, S. (1978). Patterns of attachment: A psychological study of the strange situation. Hillsdale, NJ: Lawrence Erlbaum.

Andersen, S. M., Reznik, I., \& Manzella, L. M. (1996). Eliciting facial affect, motivation, and expectancies in transference: Significant other representations in social relations. Journal of Personality and Social Psychology, 71, 1108-1129.

Baldwin, M. W., Keelan, J. P. R., Fehr, B., Enns, V., \& KohRangarajoo, E. (1996). Social-cognitive conceptualization of attachment working models: Availability and accessibility effects. Journal of Personality and Social Psychology, 71, 94-109.

Bowlby, J. (1969). Attachment and loss: Vol. 1. Attachment. New York: Basic Books.

Brennan, R. L. (2001a). Generalizability theory. New York: Springer.

Brennan, R. L. (2001b). Manual for $m$ GENOVA (Version 2.1). Iowa City: Iowa Testing Programs Occasional Papers (Number 50).

Buist, K. L., Dekovic, M., Meeus, W. H., \& van Aken, M. A. G. (2004). Attachment in adolescence: A social relations model analysis. Journal of Adolescent Research, 19, 826-850.

Cassidy, J., \& Shaver, P. R. (Eds.). (1999). Handbook of attachment: Theory, research and clinical applications. New York: Guilford.

Collins, N. L., \& Feeney, B. C. (2000). A safe haven: An attachment theory perspective on support seeking and caregiving in intimate relationships. Journal of Personality and Social Psychology, 78, 1053-1073.

Collins, N. L., \& Feeney, B. C. (2004). Working models of attachment shape perceptions of social support: Evidence from experimental and observational studies. Journal of Personality and Social Psychology, 87, 363-383.

Collins, N. L., Guichard, A. C., Ford, M. B., \& Feeney, B. C. (2004). Working models of attachment: New developments and emerging themes. In S. W. Rholes \& J. A. Simpson (Eds.), Adult attachment: Theory, research, and clinical implications (pp. 196-239). New York: Guilford.

Cook, W. L. (1994). A structural equation model of dyadic relationships within the family system. Journal of Consulting and Clinical Psychology, 62, 500-509.

Cook, W. L. (2000). Understanding attachment security in family context. Journal of Personality and Social Psychology, 78, 285-294.

Cronbach, L. J., Gleser, G. C., Nanda, H., \& Rajaratnam, N. (1972). The dependability of behavioral measurements: Theory of generalizability for scores and profiles. New York: John Wiley.

Davis, M. H., Morris, M. M., \& Kraus, L. A. (1998). Relationshipspecific and global perceptions of social support: Associations with well-being and attachment. Journal of Personality and Social Psychology, 74, 468-481.

Fraley, C. R., \& Brumbaugh, C. C. (2004). A dynamical systems approach to conceptualizing and studying stability and change in attachment security. In S. W. Rholes \& J. A. Simpson (Eds.), Adult attachment: Theory, research, and clinical implications (pp. 86132). New York: Guilford.

Fraley, R. C., \& Shaver, P. R. (2000). Adult romantic attachment: Theoretical development, emerging controversies, and unanswered questions. Review of General Psychology, 4, 132-154.

Fraley, R. C., Waller, N. G., \& Brennan, K. A. (2000). An item response theory analysis of self-report measures of adult attachment. Journal of Personality \& Social Psychology, 78, 350-365. 
Gonnerman, M. E., Jr., Parker, C. P., Lavine, H., \& Huff, J. (2000). The relationship between self-discrepancies and affective states: The moderating roles of self-monitoring and standpoints on the self. Personality \& Social Psychology Bulletin, 26, 810-819.

Griffin, D. W., \& Bartholomew, K. (1994). Models of the self and other: Fundamental dimensions underlying measures of adult attachment. Journal of Personality and Social Psychology, 67, 430-445.

Heatherton, T. F., \& Polivy, J. (1991). Development and validation of a scale for measuring state self-esteem. Journal of Personality \& Social Psychology, 60, 895-910.

Higgins, E. T. (1987). Self-discrepancy: A theory relating self and affect. Psychological Review, 94, 319-340.

Higgins, E. T. (1996). Knowledge activation: Accessibility, applicability, and salience. In E. T. Higgins \& A. W. Kruglanski (Eds.), Social psychology: Handbook of basic principles (pp. 133-168). New York: Guilford.

Higgins, E. T., Bond, R., Klein, R., \& Strauman, T. (1986). Selfdiscrepancies and emotional vulnerability: How magnitude, accessibility, and type of discrepancy influence affect. Journal of Personality and Social Psychology, 51, 5-15.

Kenny, D. (1994). Interpersonal perception: A social relations analysis. New York. Guilford.

Kenny, D. A., Mohr, C. D., \& Levesque, M. J. (2001). A social relations variance partitioning of dyadic behavior. Psychological Bulletin, 127, 128-141.

Kenny, D. A., \& Winquist, L. A. (2001). The measurement of interpersonal sensitivity: Consideration of design, components, and unit of analysis. In J. A. Hall \& F. J. Bernieri (Eds.), Interpersonal sensitivity: Theory and measurement (pp. 265-302). Englewood Cliffs, NJ: Lawrence Erlbaum.

Kobak, R. (1999). The emotional dynamics of disruptions in attachment relationships: Implication for theory, research and clinical intervention. In J. Cassidy \& P. R. Shaver (Eds.), Handbook of attachment: Theory, research and clinical applications (pp. 21-43). New York: Guilford.

Lakey, B., Lutz, C. J., \& Scoboria, A. (2004). The information used to judge supportiveness depends on whether the judgment reflects the personality of perceivers, the objective characteristics of targets or their unique relationships. Journal of Social and Clinical Psychology, 23, 796-814

Lakey, B., \& Scoboria, A. (2005). The relative contribution of trait and social influences to the links among perceived social support, affect and self-esteem. Journal of Personality, 73, 361-388.

Merlo, L. J. (2005). The relative contribution of trait and social influences in the links among adolescent attachment, coping and depressive symptoms. Unpublished doctoral dissertation, Wayne State University.

Mikulincer, M. (1995). Attachment style and the mental representation of the self. Journal of Personality and Social Psychology, 69, $1203-1215$.
Mikulincer, M., \& Shaver, P. R. (2004). Security-based self-representations in adulthood: Contents and processes. In S. W. Rholes \& J. A. Simpson (Eds.), Adult attachment: Theory, research, and clinical implications (pp. 159-195). New York: Guilford.

Mooney, C. Z., \& Duval, R. D. (1993). Bootstrapping: A nonparametric approach to statistical inference. Thousand Oaks, CA: Sage.

Neely, L. C., Lakey, B., Cohen, J. L., Barry, R., Orehek, E., Abeare, C. A., et al. (2006). Trait and social processes in the link between social support and affect: An experimental laboratory investigation. Journal of Personality, 74, 1015-1046.

Pierce, G. R., Sarason, I. G., \& Sarason, B. R. (1991). General and relationship-based perceptions of social support: Are two constructs better than one? Journal of Personality and Social Psychology, 61, 1023-1039.

Pietromonaco, P. R., \& Feldman Barrett, L. (2000). The internal working models concept: What do we really know about the self in relation to others? Review of General Psychology, 4, 155-175.

Rholes, S. W., \& Simpson, J. A. (2004a). Adult attachment: Theory, research, and clinical implications. New York: Guilford.

Rholes, S. W., \& Simpson, J. A. (2004b). Attachment theory: Basic concepts and contemporary questions. In S. W. Rholes \& J. A. Simpson (Eds.), Adult attachment: Theory, research, and clinical implications (pp. 3-14). New York: Guilford.

Simpson, J. A., \& Rholes, S. W. (2004). Anxious attachment and depressive symptoms: An interpersonal perspective. In S. W. Rholes \& J. A. Simpson (Eds.), Adult attachment: Theory, research, and clinical implications (pp. 408-437). New York: Guilford.

SPSS, Inc. (2002). SPSS for Windows (Release 11.5.0). Chicago: Author.

Strauman, T. J. (1989). Self-discrepancies in clinical depression and social phobia: Cognitive structures that underlie emotional disorders? Journal of Abnormal Psychology, 98, 14-22.

Strauman, T. J., \& Higgins, E. T. (1987). Automatic activation of selfdiscrepancies and emotional syndromes: When cognitive structures influence affect. Journal of Personality and Social Psychology, 53, 1004-1014.

Strodl, E., \& Noller, P. (2003). The relationship of adult attachment dimensions to depression and agoraphobia. Personal Relationships, 10, 171-185.

Strube, M. J. (2000). Reliability and generalizability theory. In G. G. Laurence \& P. R. Yarnold (Eds.), Reading and understanding MORE multivariate statistics (pp. 23-66). Washington, DC: American Psychological Association.

Watson, D., Clark, L., \& Tellegen, A. (1988). Development and validation of brief measures of positive and negative affect: The PANAS scales. Journal of Personality and Social Psychology, 54, 1063-1070.

Received January 2, 2006

Revision accepted August 17, 2006 